\title{
Ranking motivational factors of teachers in Urmia using AHP
}

\author{
Azizzadeh, Fariba $\measuredangle$ \\ Islamic Azad University, Science and Research Branch, Iran (Sazizzadeh2010@yahoo.com) \\ Soltani, Iraj \\ Islamic Azad University, Science and Research Branch, Isfahan, Iran (i.soltani@msc.ir)
}

Azizzadeh, Samira

Expert in Day Bank, Urmia, Iran (Samiraaz2011@yahoo.com)

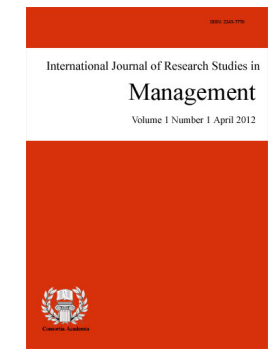

ISSN: $2243-7770$ Online ISSN: 2243-7789

OPEN ACCESS

Malmir, Ameneh

Malayer Branch, Islamic Azad University, Malayer, Iran (amenehmalmir@gmail.com)

Azizzadeh Aghdam, Kobra

Urmia University,Iran (Kobra_azizzadeh@yahoo.com)

\section{Abstract}

The aim of this study was to identify and rank the motivating factors of teachers work as free employees in schools district 1 in Urmia. This study was done in 2011 and its population included 33 and due to its small size, the sample equals the population. The study was analyzed through hierarchical AHP method by using statistical software. The study examined social interaction, organizational culture, skill factors, competition and personal and educational factors. Reliability coefficient of $97 \%$.was estimated by using Cronbach's alpha. Findings show that, highest and lowest credit rating among social interactions factors relate to being approved by the director. The highest and lowest scores among the organizational factors related to teachers' good activity and students' interest. Working outside the home has the highest score among skill factors and experience has the minimum score. The degree of competition among teachers with different fields of study allocated higher score than teachers with same field of study. Group rate discover talents have been recognized as the main training factor and the least important factor, respectively. Also mental preoccupations, material rewards, work ethic and passion have been preferred among the individual factors.

Keywords: motivation; ranking motivational factors; AHP; teachers 


\section{Ranking motivational factors of teachers in Urmia using AHP}

\section{Introduction}

Creating incentives for greater effort towards organizational goals has always been a concern of management. For this purpose, various theories have been given as well as various incentive programs. Managers are trying to increase employee motivation and other executives by applying these theories and implementations of incentive programs. Motivation is one of the factors that drive the performance of the organization and ultimately can have a significant impact. Teachers as employees who are very influential in the country's future, as people are the key to the future. Motivations of the teachers also have been in the attention of the training system and also parents. So the recognizing and rating of these motivations are in public attention. Taking into account its specific situation and identifying the motivational factors would be useful in determining maximum capacity of teachers in school and whole country. Thus this study aimed to determine and rank the motivation factors based on the situations and teachers' specific job properties.

\section{Research Literature}

According to internal and external researches several factors as factors affecting employee motivation has been identified. Akhundi Bunab et al. (2011) showed that if managers have more internal locus of control they will have a positive impact on their staff. In fact, the more external control of the organization management, the more reduction of its employees' motivation (Akhundi Bunab et al., 2011). Based on the Ameri (2009), Participation in decision-making, human relations climate in the organization has a positive relationship with job motivation (Seyyed Ameri, 2009). Bakhtiari et al. (2009) in their study determined that there is an inverse correlation between emotional exhaustion and motivation. The increased compensation, improved working conditions, interrelationships, and security and officials as health factors, thereby increase the efficiency of the result (Bakhtiari et al, 2009).

Shafizadeh (2002) examined 4 variables, personal characteristics, job characteristics, workplace characteristics and features of the external environment among physical educators. He also notes that there is a significant relationship between motivation and education, but work experience does not affect the amount of Job motivation.(Shafeezadeh, 2002). Farhangi et al. in 2006 stated employees believe that relationship between interpersonal and intrapersonal are effective in their work, but they will not alter the relationship between hero and the person's motivation. The relationship between the spiritual realms and individual hero is Psycho Realm of employees. The relationship between intrapersonal includes social and outside dimensions of life. More motivational process is more external than internal and staffs believe that work life and spiritual life are different (Farhangi et al., 2006).

Another study which was conducted in Tehran among education consultants shows that significant positive correlations exist between the organizational culture of entrepreneurship and job motivation partnerships. Women Trip Advisor also had higher levels of motivation and organizational culture. As a result, greater degree of flexibility, employee autonomy, creativity and initiative in working place increase the level of job motivation (Gholami Hiedarabadi, 2011). Radafshar (2010) in his research mentioned that factors such as weather conditions, use of credits, sports clubs and leisure centers, proper sanitation, and working in the private sector and having an adequate financial resources has a significant influence on motivation(Radafshar et al., 2011).

Other results of Ostvar et al. survey in 82 shows that the hierarchy of needs from the perspective of managers and employees has a good attunement and the motivation of employees and managers from the perspective of a difference is not observed. Also, managers and employees mentioned respect and dignity as the most important needs (Ostvar et al., 2003). However, another study conducted by Kajbaf and colleagues 
demonstrated that there is significant differences in motivational factors in terms of employees and supervisors. Although the biological needs of the staff were mentioned, the need to respect the community was in priority, and it was the most important need against what is believed to be guardians. This research shows that physiological needs is important in view of careers while employees posed need for growing as the most critical needs (Kajbaf et al., 2005).

Another study shows that having a definite goal can develop the employees' motivation and also training programs is a factor for determination.(Habibipour et al., 2009). Mahmoudi and Poukazem stated in their study the most and the least important factors among the internal factors of motivation as the job identity (52\%) and responsibility (34\%), respectively. Among the outside factors of motivation, among the external factors of motivation, supervision and monitoring $(51 \%)$ were the most important factor, and payroll (29 percent) was the least important factor. Results suggest that internal factors are more important in motivating than extrinsic factors (Mahmoudi \& Pourkazem, 2007).

Research of Ejeyee et al. shows that four styles of Motivational empathy, conformity, objectivity, and the other-base were the key aspects of the stronger predictors of job performance (Ajhei et al., 2009). In other research, the need for respect got the highest score among the motivation factors. Also the needs for physiologic needs of women were greater than men and they lose the respect and love and kindness by aging (Keshtkaran et al., 2006). The study of Pourhadi et al. (2009) shows that there isn't any relation between age and sex with motivation potential factors.

In another ranking among the Oil Company Products, the factors of non-financial extrinsic rewards, extrinsic rewards and financial rewards and in the end the internal (intrinsic) incentives have the greatest impact on increasing the motivation. Also, just to get a sense of the work, performance evaluation of implementation, providing advancement opportunities for all employees and job specifications, fitness between jobs and decent and competent leadership are also important (Khademi et al., 2010).

Rao in his research measures the production of urea and nitrogen and then implemented group's motivation in the organization and ultimately measures productivity again (Rao, 2006). The results show that production level increases by motivation increment. Another study was conducted in 133 companies that implement employee welfare programs. As a result, employee welfare plans (including year-end bonuses, flexible time etc.) have a greater effect on employee motivation and have less effect on productivity. The staff and directors demand financial needs and gender differences can lead to welfare pleas. Workers with different levels of education and employment opportunities have different understanding of the effects of employee welfare. The findings indicate that employee benefit programs are more effective on younger employee job performance (Hong et al., 1995).

One of the researches in 12 World Bank that is based in Istanbul has been sent to staff on-line questionnaire via email that included all the managers and employees. The number of samples was 116 of 12 banks in Istanbul. According to the survey the results of internal and external motivation influence on employee performance (Gungor, 2011). Furthermore, studies within the higher education in the Philippines is centered on four key result areas that include quality of teaching and research, support for students, relations with the community, and management of resources (Ching, 2013). A research in Nigeria concluded that challenges that teachers faced require effective application of systemic model and goal-oriented partnership between the school and other stakeholders as means of improving the quality of teaching and learning for the attainment of the set goals (Ayeni, 2012).

Another study, evaluated the merit of managers is crucial to increase employee motivation. According to the study, only 23 of the 124 Directors used motivational techniques. Our results indicate that managers purposefully assess their motivation skills and employees believe that loyalty is based on their motivation (Lourdes et.al, 2011). Research on 124 director in Bosnia-Herzegovina confirm these findings and suggests that fewer than one in five managers, often apply all the motivation techniques and the rest used less tongues. This reason would 
be personal attitude, environment and climate that do not allow them to maneuver. The managers try to assess their skills in motivating others. (Rahimic et al, 2012). Effective measures to improve the employees' motivation in project-based organizations are justice orientation, leadership style, work environment, staff development and targeting.

Some motivational techniques in project-oriented and project-oriented organizations are equal such as the financial and non-financial rewards. Motivational techniques in project-driven organizations are often to focus on communication. The point that needs to be addressed by the project is that the level of motivation will change in the project. Motivation is high in the beginning and decreases with time. Therefore it is important to managers motivate the members of the project with special attention in the final stages (Rahimic et al., 2012).

Locus of individuals' control (those who believe they have control over their own destiny) has a meaningful relationship with a sense of satisfaction, motivation, and behavioral tendencies. There are two types of internal and external locus of control. People with internal locus of control believe that they are the master of your own destiny and unscrupulous people, who are awake and directive. Furthermore, they believe that there is a strong correlation between the results and their work. People with external locus of control are those that believe they have no impact on their future and are given their passive role in dealing with the external environment. Their results are compared to external factors or chance (W. H. NG. et al., 2006). It is expected that negative emotions detriment learning from mistakes by reducing their motivation to learn from errors. Mistakes intolerance will increase negative emotions. In fact, emotional stability is recommended to reduce negative emotions. In fact, there is a positive relationship between the negative emotion and motivation to learn from mistakes (Zhao, 2011).

\section{Aim and Central Research Questions}

The aim of this study was to identify and rank motivational factors (social, organizational culture, individual factors, and training, competition and skill factors) of teachers. AHP method is used to achieve this goal. Also the paradigm of this paper is based on modern one. The research questions are divided into six categories. Questions about social interactions are based on relationships with parents, respect for students, maintaining social status, credit and approved by the director. The core questions will examine the organizational culture in the classroom atmosphere, good and bad performance of teachers, and student's interests. Personal factors are raised questions about the remuneration of material prize, educational interest, work ethic and preoccupations outside the classroom.

Questions about participation in educational programs, group ranking and discovering training talents were asked. For the competition factor some questions such as the degree of competition among teachers is used. Finally, questions such as working outdoors, master the skills and experience of the employees are questioned. This study is practical and applied to identify and rank the teachers motivating factors in the District 1 in Urmia. The study population consisted of all teachers (free human source) public Girls High School was 33 persons in District1. These 33 people were selected for the collecting data. Due to the low number of samples, they were assumed equal. For data collection a questionnaire containing 22 questions were used to ask about various aspects of the motivational factors. Range of options was divided based on the highest score of 9 to lowest score. Cronbach's alpha was used to test the reliability and validity of the questionnaires. The Cronbach's alpha was $97 \%$ that it is acceptable. The statistical software was used for data analysis.

\section{Data Analysis}

Findings from this study suggest that among social interactions agents, the highest rating relates to the credibility and reputation $(0.213)$ and the lowest rate relates to the approbation by the director $(0.182)$. The rest scores were divided between these two scores. The following table shows the results of social interaction. 
Table 1

Matrix Mean Geometric scores of social interaction preferences

\begin{tabular}{lrrrrr}
\hline \multicolumn{1}{c}{ Social interaction } & $\begin{array}{c}\text { Relationship } \\
\text { with Parents }\end{array}$ & $\begin{array}{c}\text { Respect for } \\
\text { students }\end{array}$ & $\begin{array}{c}\text { Conservation } \\
\text { status }\end{array}$ & $\begin{array}{c}\text { Reputation } \\
\text { achievement }\end{array}$ & $\begin{array}{c}\text { Approved by } \\
\text { the Director }\end{array}$ \\
\hline Relationship with Parents & 1 & 1.053 & 1.121 & 0.976 & 1.074 \\
Respect for students & 0.948 & 1 & 1.064 & 0.926 & 1.009 \\
Conservation status & 0.89 & 0.938 & 1 & 0.869 & 0.954 \\
Reputation achievement & 1.038 & 1.078 & 1.144 & 1 & 1.096 \\
Approved by the Director & 0.97 & 0.977 & 1.054 & 0.907 & 1 \\
\hline
\end{tabular}

Table 2

Ranking of social interaction

\begin{tabular}{ccl}
\hline Incompatibility Factor & The relative importance factors & \multicolumn{1}{c}{ Social interaction } \\
\hline \multirow{2}{*}{0.015} & 0.213 & Reputation achievement \\
& 0.207 & Relationship with Parents \\
& 0.196 & Respect for students \\
& 0.184 & Conservation status \\
& 0.182 & Approved by the Director \\
\hline
\end{tabular}

Among the factors of organizational culture, corporation of good teacher, bad teacher performance, classroom environment, and student interest factors have been evaluated. The table below shows the matrix mean geometric of Corporate Culture.

Table 3

Matrix Mean Geometric scores of preference organizational culture

\begin{tabular}{|c|c|c|c|c|}
\hline Organizational culture & Class environment & $\begin{array}{l}\text { Bad teacher } \\
\text { performance }\end{array}$ & $\begin{array}{l}\text { Good teacher } \\
\text { performance }\end{array}$ & $\begin{array}{c}\text { Students' } \\
\text { interest }\end{array}$ \\
\hline Class environment & 1 & 0.944 & 0.618 & 1.078 \\
\hline Bad teacher performance & 1.058 & 1 & 0.655 & 1.141 \\
\hline Good teacher performance & 1.726 & 1.525 & 1 & 1.556 \\
\hline Students' interest & 0.974 & 0.875 & 0.641 & 1 \\
\hline
\end{tabular}

\section{Table 4}

Ranking of organizational culture

\begin{tabular}{ccl}
\hline Incompatibility Factor & The relative importance factors & \multicolumn{1}{c}{ Organizational culture } \\
\hline \multirow{2}{*}{0.01} & 0.345 & Good teacher performance \\
& 0.228 & bad teacher performance \\
& 0.216 & Class environment \\
& 0.208 & Students' interest \\
\hline
\end{tabular}

According to the results of the survey among demographic factors preoccupations gain highest score $(0.338)$ and Interest of discipline and work ethics are lowest score (0.196). Material rewards point is 0.269, between these factors.

\section{Table 5}

Matrix Mean Geometric preference scores for individual factors

\begin{tabular}{lrrrr}
\hline Personal factors & Material rewards & Interest of discipline & Conscientious & Preoccupations \\
\hline Material rewards & 1 & 1.333 & 1.539 & 0.766 \\
Interest of discipline & 0.749 & 1 & 1.003 & 0.574 \\
Conscientious & 0.815 & 0.978 & 1 & 0.57 \\
Preoccupations & 1.308 & 1.738 & 1.731 & 1 \\
\hline
\end{tabular}




\section{Table 6}

Ranking of factors affecting individual motivation

\begin{tabular}{ccl}
\hline Incompatibility factor & The relative importance factors & \multicolumn{1}{c}{ Personal factors } \\
\hline \multirow{2}{*}{0.017} & 0.338 & Preoccupations \\
& 0.269 & Material rewards \\
& 0.196 & Conscientious \\
& 0.196 & Interest of discipline \\
\hline
\end{tabular}

According to these results, we conclude that incentives effective prioritization of education are: 1 - Group ranking, 2 - participation in classes, 3 - Science Rank, 4 - discovering the talents. The following table shows the details of the results.

\section{Table 7}

Matrix Mean Geometric preference scores of educational factors

\begin{tabular}{lrrrr}
\hline \multicolumn{1}{c}{ Educational factors } & Participation in classes & Group ranking & Discovering the talents & Science Rank \\
\hline Participation in classes & 1 & 0.957 & 1.05 & 1.289 \\
Group ranking & 1.038 & 1 & 1.096 & 1.346 \\
Discovering the talents & 1.02 & 0.925 & 1 & 1.213 \\
Science Rank & 0.926 & 0.793 & 0.813 & 1 \\
\hline
\end{tabular}

\section{Table 8}

Ranking of factors influencing educational motivation

\begin{tabular}{ccl}
\hline Incompatibility factor & The relative importance factors & Educational factors \\
\hline \multirow{2}{*}{0.232} & 0.270 & Group ranking \\
& 0.259 & Participation in classes \\
& 0.251 & Science rank \\
& 0.216 & Discovering the talents \\
\hline
\end{tabular}

The results show that among skilled agents the highest score is for work outside the home (0.374) and experience got the lowest score (0.308), the following table indicates the results.

\section{Table 9}

Matrix Mean Geometric scores of skill preferences

\begin{tabular}{lrrr}
\hline \multicolumn{1}{c}{ Skilled agents } & Work outside the home & Mastery of the subject & \multicolumn{1}{c}{ Experience } \\
\hline Work outside the home & 1 & 1.203 & 1.201 \\
Mastery of the subject & 0.86 & 1 & 1.008 \\
Experience & 0.815 & 0.99 & 1 \\
\hline
\end{tabular}

\section{Table 10}

Ranking of factors affecting motivation skills

\begin{tabular}{ccl}
\hline Incompatibility factor & The relative importance factors & Skilled agents \\
\hline \multirow{2}{*}{0.009} & 0.374 & Work outside the home \\
& 0.316 & Mastery of the subject \\
& 0.308 & Experience \\
\hline
\end{tabular}

The following tables show relating of competition and ranking of these factors. 


\section{Table 11}

Matrix Mean Geometric preference scores of competitive factors

\begin{tabular}{lcc}
\hline \multicolumn{1}{c}{ Competition factors } & $\begin{array}{c}\text { Teachers compete with the same } \\
\text { majors }\end{array}$ & $\begin{array}{c}\text { Competition with other teachers in } \\
\text { the field }\end{array}$ \\
\hline $\begin{array}{l}\text { Teachers compete with the } \\
\text { same majors }\end{array}$ & 1 & 0.729 \\
$\begin{array}{l}\text { Competition with other } \\
\text { teachers in the field }\end{array}$ & 1.342 & 1 \\
\hline
\end{tabular}

\section{Table 12}

Rating competitive factors affecting motivation

\begin{tabular}{ccl}
\hline Incompatibility factor & The relative importance factors & \multicolumn{1}{c}{ Competition factors } \\
\hline 0.00 & 0.575 & Competition with other teachers in the field \\
& 0.423 & Teachers compete with the same majors \\
\hline
\end{tabular}

The findings are presented in the following model, which represents the motivational factors affecting teachers.

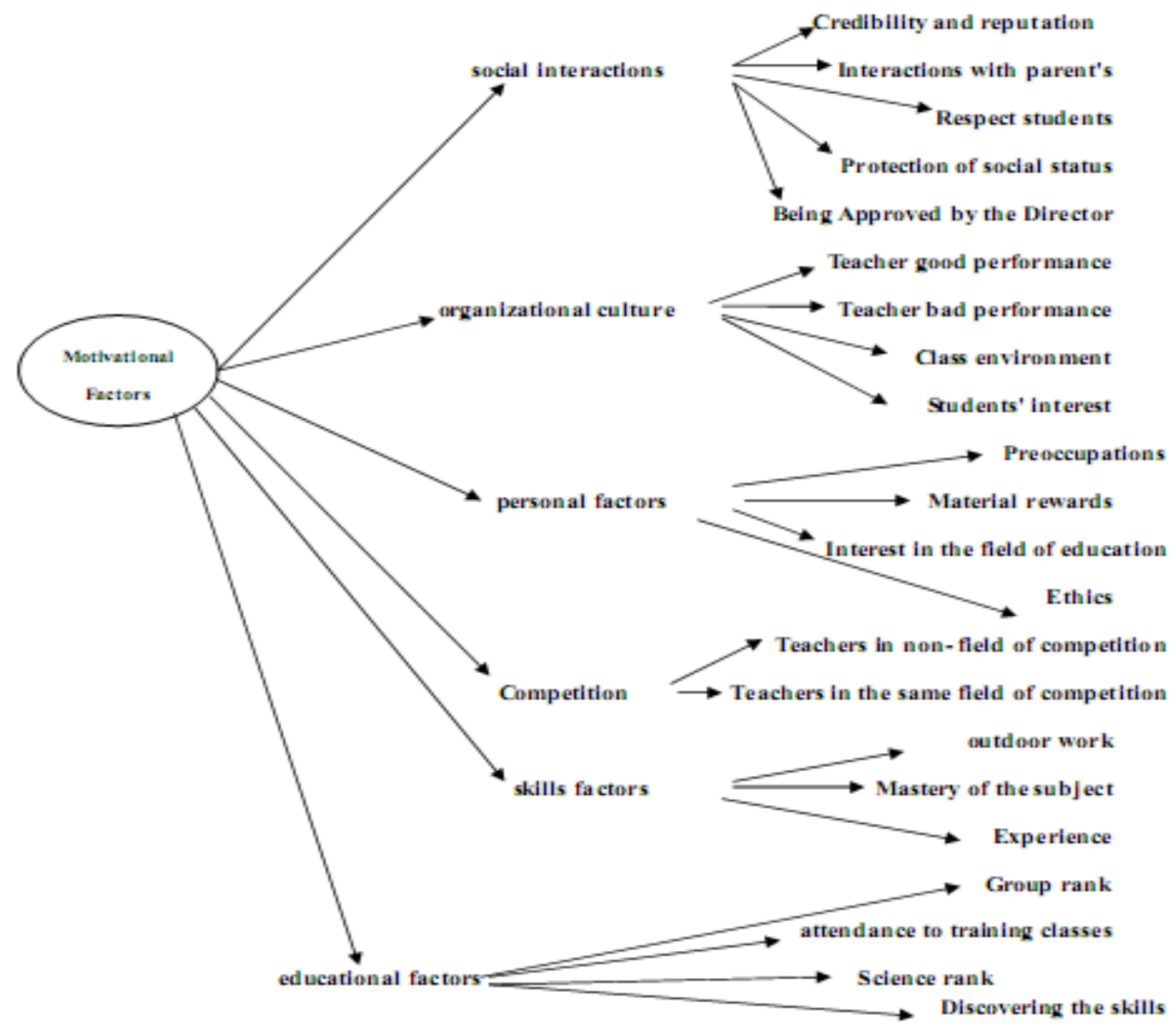

Model 1. Proposed model

\section{Conclusion}

Individual characteristic of the employees' motivation is an important factor (Shafizadeh, 2002) it can be 
seen in the analysis results that teachers preoccupations and psychological impact factors is the most important factor among the individual motivation. Thus reducing the psychological preoccupations can be effective in motivating employees. If the corporate cultures develop in entrepreneurship and participation in the Promotion, it will also improve job motivation (Gholami Hiedarabadi, 2011). To analyze the results of this study, the most important aspect of organizational performance is well known as a good performance of the teacher. The study of Malmir about the social relations, the ability to communicate with others has identified as the most important factor (Malmir, 2009). In the findings of the present study obtaining reputation is accounted as the highest score in the field of social interaction. Ostvar research (2003) and Keshtkaran (2006) also confirmed the survey results. (Ostvar et al., 2003; Keshtkaran et al., 2006). The results show that the degree of competition between teachers of non-same filed is more important than competition between teachers in the same field and working outside the home is the most important motivational factors. Education is an important factor in motivating staff (Habibi et al., 2009) that based on the present study team rankings has been identified among the most important factors of training. So as a result, greater investment on teachers' training is recommended.

Implication of this research is the identification of motivational factors of teachers. By doing this, the managers of school can focus on important factors that motivate the teachers so the satisfactory and happiness of them will increase. This research focuses on ranking the motivational factors of teachers by using AHP method. The using of this method for the aim of identifying motivational factors is a new thing in this background.

\section{References:}

Ajhei, J., Khodapanahi, M. K., Fathi Ashtiani, A., Sabeti, A., Ghanbari, S., \& Seyyed Mousavi, P. S. (2009). Interaction between personality and learning styles and motivation in job performance [In Persian]. Journal of Olume Raftari, 3(4), 301-310.

Akhundi Bunab, H. A., Mosavi Shojai, Z., Pirkhaefi, A. R., \& Mehdipour Moghaddam, M. (2011). The relationship between locus of control managers motivate employees, Islamic Azad University, East Azerbaijan Province, 89-88 years [In Persian]. Journal of Farasoye Modiriat, 55(17), 33-52.

Ayeni, A. J. (2012). Achieving quality and standards in the management of Nigerian secondary schools: Policy goals, current practice, trends, challenges, and opportunities. International Journal of Research Studies in Management, 1(2), 37-45. http://dx.doi.org/10.5861/ijrsm.2012.v1i2.46

Bakhtiari, A., Godarzi, M., Hamidi, M., \& Ghorbani, M. H. (2009). Motivational - health factors and physical education experts from universities, government job burnout Tehran [In Persian]. Journal of Modiriate varzeshi, 3, 135-150.

Ching, G. S. (2013). Higher education accreditation in the Philippines: A literature review. International Journal of Research Studies in Management, 2(1), 1-12. http://dx.doi.org/10.5861/ijrsm.2012.162

Farhangi, A. A., \& Rastegar, A. A. (2006). Presentation and explanation-based incentive model of spirituality staff [In Persian]. Journal of Shahed University, 13(20).

Gholami Hiedarabadi, Z. (2011). The relationship between components of organizational culture and motivation and burnout in Tehran Advisors [In Persian]. Journal of Counseling and Psychotherapy, 2(7), 103-121.

Güngör, P. (2011). The relationship between reward management system and employee performance with the mediating role of motivation: A quantitative study on global banks. Procedia Social and Behavioral Sciences, 24, 1510-1520. http://dx.doi.org/10.1016/j.sbspro.2011.09.029

Habibipour, B., Vanaki, Z., \& Hajizadeh, E. (2009). The effect of goal setting theory on job motivation by nurse managers [In Persian]. Journal of Parastari Iran, 22(57), 67-76.

Hong, J. C., Yang, S. D., Wang, L. J., Chiou, E. F., Sun F. Y., \& Huang, T. L. (1995). Impact of employee benefits on work motivation and productivity. The International Journal of Career Management, 7(6),10-14. http://dx.doi.org/10.1108/09556219510098064

Kajbaf, M. B., \& Pourkazem, T. (2005). Staff and supervisors' views of the National Iranian Oil Company: motivational factors and its relationship with job satisfaction [In Persian]. Journal of Cognitive Science, 7(1), 67-73. 
Ranking motivational factors of teachers in Urmia using AHP

Keshtkaran, A., Kharazmi, E., \& Youssefi, S. (2006). Motivational needs of nurses in university hospitals based on Maslow's hierarchy of needs (2006) [In Persian]. Journal of Modiriate Salamat, 9(24), 45-50.

Khademi, Z., Fakhrzad, M., \& Akrami, M. K. (2010). Prioritize the factors motivating staff to increase productivity (Case Study: Gulf Oil Products Distribution Company) [In Persian]. Journal of management and Human Resource Management in the Oil Industry, 4(13), 85-104.

Lourdes, M., Meira Soares, V., Brites, R., Brites Ferreira, J., \& Maria Rocha, G. O. (2011). A look to academics job satisfaction and motivation in Portuguese higher education institutions. Procedia Social and Behavioral Sciences, 29, 1715-1724. http://dx.doi.org/10.1016/j.sbspro.2011.11.417

Mahmoudi, H., Ebrahimian, A., Soleymani, M., Ebadi, A., Hafezi, S., Feizi, F., \& Sadeghi Sherme, M. (2007). Factors motivating nurses in Special parts [In Persian]. Journal of Olome Raftari, 1(2), 171-178.

Malmir, A., (2009). Ranking Factors affecting labor productivity using the AHP and TOPSIS [In Persian]. Unpublished Masteral thesis.

Ostvar, R., Mousavi, A. M., Ghafarian Shirazi, H. R., \& Abbasi Moghaddam, M. A. (2003). Factors influencing employee motivation, staff and administrators from the perspective of medical science [In Persian]. Journal of Armaghane Danesh, 8(31), 21-26.

Pourhadi, S., Kamali, M., Khalesi, N., \& Fahimi Malahat, A. (2009). Determine the motivational potential of jobs Rehabilitation in welfare centers in Tehran on the basis of potential motivation [In Persian]. Journal of Modiriate Salamat, 2(37), 57-64.

Radafshar, Z., Hosseini Tashnizi, S., Solati, S. M., Naderi, N., \& Mahbobi, A. (2010). Motivational Factors affecting retention of faculty employed in Hormozgan University of Medical Sciences in 1986 [In Persian]. Medical Journal of Hormozgan, 14(3), 164-166.

Rahimic, Z., Resic, E., \& Kozo, A. (2012). Determining the Level of Management Competences in the Process of Employee Motivation. Procedia-Social and Behavioral Sciences, 41, 535-543. http://dx.doi.org/10.1016/j.sbspro.2012.04.066

Rao, P. (2006). Motivation model for improving productivity in a Manufacturing unit - a success story. International Journal of Productivity and Performance Management, 55(5), 430-436. http://dx.doi.org/10.1108/17410400610671453

Seyyed Ameri, M. H. (2009). Explaining the relation between participative management as an effective method of employee motivation and physical education offices in West Azerbaijan [In Persian]. Journal of Modiriate Varzeshi, 1, 5-7.

Shafizadeh, A. (2002). Job Motivation Factors of Physical Education Teachers [In Persian]. Journal of Harakat, 14, 53-67.

Tohidi, H., \& Jabbari, M. M. (2012). Role of human aspects in project management. Procedia-Social and Behavioral Sciences, 31, 837-840. http://dx.doi.org/10.1016/j.sbspro.2011.12.152

W. H. Ng. Thomas, L. Jorensen, \& T. Eby Lillian (2006). Locus of control at work: a meta-analysis. Journal of organizational Behavior, 27, 1057-1087. http://dx.doi.org/10.1002/job.416

Zhao, B. (2011). Learning from errors: The role of context, emotion, and personality. Journal of organizational Behavior, 32, 435-463. http://dx.doi.org/10.1002/job.696 
Azizzadeh, F., Soltani, I., Azizzadeh, S., Malmir, A., \& Azizzadeh Aghdam, K. 